\title{
EDITORIAL \\ Do hematopoietic stem cells get old?
}

Leukemia (2017) 31, 529-531; doi:10.1038/leu.2016.301

In many countries of the world, the proportion of elderly people will rise very substantially in the upcoming decades. As a result, the number of patients that present with age-related diseases will also increase. This relates to neurodegenerative conditions, such as Alzheimer's disease, that many people will instantly link to an aging society, but it also includes multiple hematological syndromes that display clear increases in incidence with advanced age (Figure 1). Whereas in the United States for a long time, the leading cause of death has been heart disease, this was recently replaced by cancer. ${ }^{1}$ More old people will result in more patients with leukemia and in increasing health care costs for their treatment (Figure 2).

In addition to these clear-cut hematological diseases, there are multiple other (pre-)clinical manifestations that may be affected by malfunctioning of the hematopoietic system. These include, for example, an increased susceptibility to infections (due to reduced numbers and functioning of lymphocytes), ${ }^{2}$ reduced vaccination efficiency ${ }^{3}$ and an increased risk of arteriosclerosis (due to altered macrophage activity), anemia ${ }^{4}$ and may be even some neurological conditions (as a result of loss of microglia functioning). ${ }^{5}$

To explore why many hematological diseases occur much more frequently in older people, we first need to assess what changes with age in blood (precursor) cells. Functionally, hematopoietic stem cells produce fewer progeny as they age. This has been best studied in mice. Although it is clear that old mice do not run out of stem cells, and indeed classical serial transplantation studies have documented that hematopoietic stem cells can outlive their original donor mouse, ${ }^{6}$ many age-dependent detrimental stem cell phenotypes have been reported. Most notably, the levels of engraftment upon transplantation of a single or a low number of purified hematopoietic stem cells are much lower when the donor cells originate from an old mouse, compared to young cells. ${ }^{7}$ These data strongly suggest that the number of mature cells produced per stem cell declines with age. However, it is not only the absolute number of mature produced cells that is declining, aging is also associated with lineage-skewing, which refers to the observation that the relative proportion myeloid and lymphoid cells changes in favor of myeloid cell production. ${ }^{8}$

It has not been very well studied to what extent the functional activity of mature, fully differentiated, blood cells, such as erythrocytes, platelets, granulocytes and macrophages, is reduced upon normal aging.

Most of the above observations have been made in mouse models, and although there is little reason to believe that human hematopoietic stem cells age differently compared with those in mice, it is important to note that we have not fully assessed to what extent aging of hematopoietic stem cells is evolutionary conserved in these two species.

What is also largely unknown is the extent to which aging of stem cells is conserved across multiple regenerating tissues. Although intuitively one would expect that mechanisms that contribute to stem cell aging may be operating in all adult stem cell populations, it is also possible that major differences exist. For example, where it is generally believed that hematopoietic stem cells are normally largely quiescent, and in fact stem cell activation is believed to be detrimental, ${ }^{9}$ in the intestinal system this appears to be quite the opposite. Intestinal stem cells have been reported to cycle very actively, yet these cells seem to be exempt from the aging process. ${ }^{10}$ In muscle stem cells, in contrast, several aging characteristics that are observed in the hematopoietic system appear to be also present. ${ }^{11}$ If the mechanisms that contribute to aging are conserved in multiple tissues, it is conceivable that interventions to prevent stem cell aging in one tissue may in fact also affect those in others.

We hypothesize that the age-dependent loss of hematopoietic homeostasis finds its origin in detrimental molecular events that first occur in primitive hematopoietic stem cells. The impaired ability of aged hematopoietic stem cells to properly balance the choice between self-renewal and differentiation may predispose to hematological and possibly other disorders. Therefore, efforts to prevent such age-dependent hematopoietic stem cell deterioration are expected to be beneficial at multiple levels.

Our understanding of the molecular causes that underly stem cell aging is still limited. A great unknown is whether impaired functioning of hematopoietic stem cells results from cell-intrinsic or rather cell-extrinsic causes. This is not only of academic interest, but is also highly relevant if approaches are developed to delay, prevent or indeed reverse stem cell aging. What would be the cell type to target, the stem cell itself, or the microenvironmental niche cell next to which it lives? Experimental transplantation studies have shown that transplanting old stem cells in a young recipient does not erase functional decline, strongly suggesting that at least a major component that contributes to stem cell aging must be a cell-intrinsic feature. ${ }^{12}$ However, it is also very clear that the constitution of aged bone marrow is very different compared with young. In aged human bone marrow, adipogenesis is much more prevalent than in young, and bones become very brittle upon aging. ${ }^{13}$ The molecular and cellular composition of the bone marrow microenvironment, which contains the elusive hematopoietic stem cell niche, has only recently been studied in significant detail ${ }^{14}$ and at current it is far from clear how this microenvironment changes during aging, and how this might contribute to decreased stem cell functioning.

An interesting observation in elderly humans is that the hematopoietic system appears to become more clonal, that is, leukocytes in the peripheral blood are derived from fewer and fewer stem cells. Initial observations on increased clonal hematopoiesis were based on skewed X-inactivation patterns in elderly females, ${ }^{15}$ but more recently the same phenomenon has been observed using whole-genome sequencing approaches. ${ }^{16,17}$ At current, it remains unclear whether oligoclonal hematopoiesis is of any clinical relevance. Several reports document very significant clonal dominance in normal elderly people, without any signs of hematological disease. $^{18-20}$ In experimental settings, it has never been documented that mice that were transplanted with a single, or very few stem cells were more prone to develop hematological disorders.

It is of great interest to assess to what extent stem cell-intrinsic aging parameters may be reversible. An interesting experimental approach showed that hematopoietic stem cells derived from induced pluripotent stem cells cells generated from aged hematopoietic stem cells were functionally equivalent to cells derived from induced pluripotent stem cells generated from young hematopoietic stem cells. ${ }^{21}$ This strongly suggests that at least a major part of the stem cell-intrinsic age-dependent decline can be reversed. This also suggests that although aged 


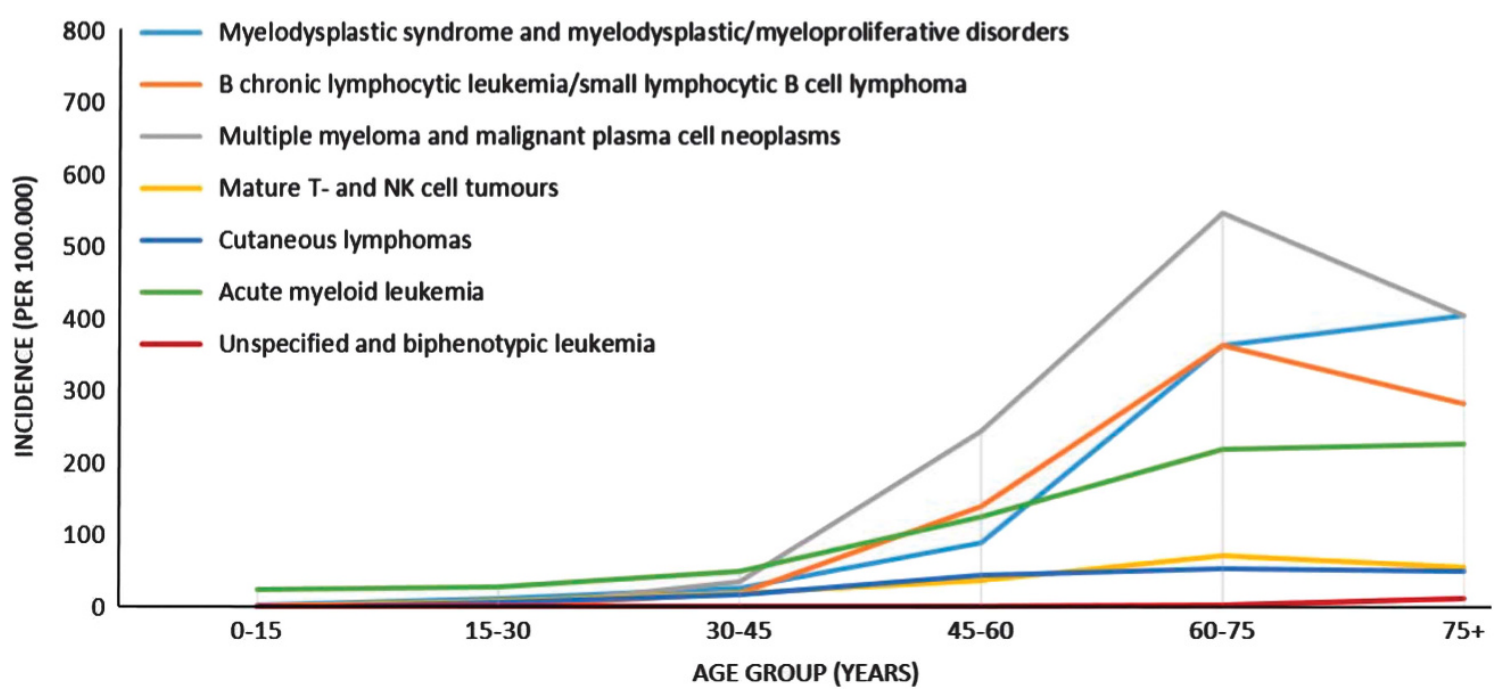

Figure 1. Incidence of several hematological diseases by age in The Netherlands in 2015.

Cost of Cancer Care by Phase of Care, Leukemia, Over 65, Male and Female, in 2010 Dollars

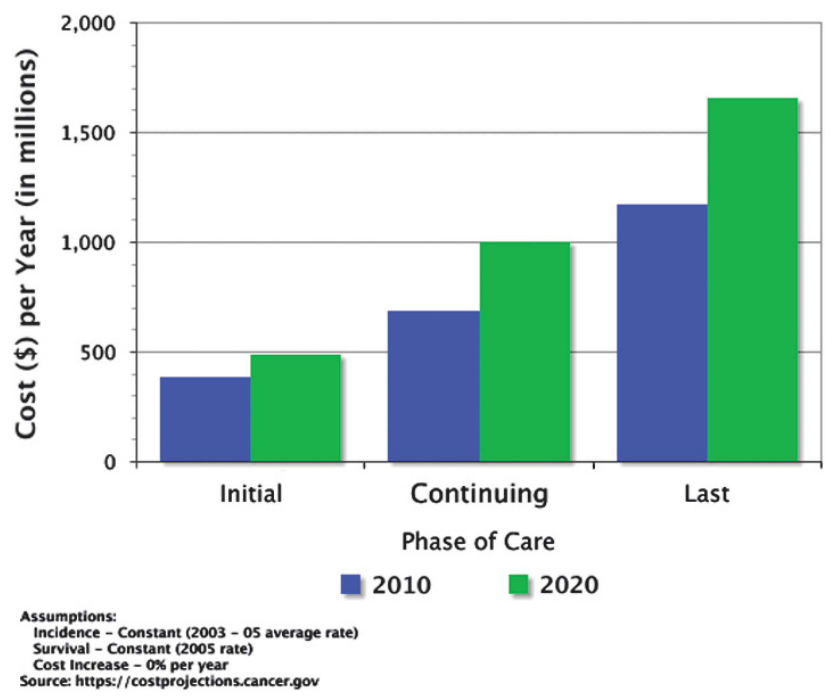

Figure 2. Cost of leukemia care by phase of care in male and female patients older than 65, in 2010 US dollars.

hematopoietic stem cells appear to display increased levels of DNA damage, ${ }^{22}$ and indeed DNA repair deficient mice and human show bone marrow pathology, ${ }^{23,24}$ dysfunctioning of normal stem cells during aging is unlikely to result from an accumulation of random genetic mutations (which obviously would not be corrected during reprogramming).

If reprogramming indeed is able to reverse hematopoietic stem cell aging, it seems plausible that epigenetic mechanisms contribute to stem cell aging. Many studies in the last decade have demonstrated that, like any adult cell type, hematopoietic stem cells show quite a distinct gene expression profile. This stem cell transcriptome must be carefully controlled by the collective consequences of a multitude of epigenetic modifications that compact or relax locally the stem cell genome. Many epigenetic writers and erasers have been shown to play important roles in hematopoietic stem cell activity. This includes, for example, Ezh2, ${ }^{25} \mathrm{Bmi}_{1}{ }^{26,27} \mathrm{Cbx7}^{28}$ and Dnmt3a. ${ }^{29}$ It appears very likely that upon a single stem cell division, some of the activating or repressing marks that are deposited or read by these proteins are not properly copied to the daughter cells, which would result in an aberrant, that is, stem cell incompatible, gene expression pattern and thus to loss of stem cell functionality. We envision that such erosion from a stem cell gene expression profile is not a digital-all or nothing-event, but rather occurs very gradually every time a cell divides.

Because of the unavoidable epigenetic differences that accumulate with each of these cell divisions, it seems very well possible that old hematopoietic stem cells require quantitatively or qualitatively different mitogenic signals from their environment compared with young stem cells. It has been well documented in mice and man that hematopoietic stem cells from fetal liver, cord blood or newly borns are fundamentally different from adult stem cells. $^{30,31}$ Some of the molecular circuitry that is associated with these stage/age-specific signals has been elucidated, ${ }^{12,32,33}$ but it is likely that much remains to be explored. Clinically, this may be of interest when cord blood-derived stem cells in the future will be used to transplant aged recipients. Will these heterochronic transplants cause problems?

In contrast to genetic lesions, aberrant epigenetic modifications can in principle be erased and corrected. This would offer ways to reverse aspects of the aging process. The most profound example of such epigenetic resetting is obviously exemplified by the process of reprogramming adult cells to pluripotency by overexpression of several transcription factors. However, it is also possible to interfere in specific epigenetic pathways by exposing cells to (small) molecules, such as histone deacetylase inhibitors or DNA demethylating agents, that inhibit specific epigenetic enzymes.

It is interesting to note that the clonal hematopoiesis that is observed in a sizeable fraction of elderly people often is associated with mutations in Dnmt3a. ${ }^{17}$ Also, mutations in several other epigenetic genes, including Ezh2 ${ }^{\text {(ref. }}{ }^{34)}$ and Tet2, ${ }^{35,36}$ are frequently found in hematological disorders. This suggests that mutations in genes coding for epigenetic enzymes may confer a proliferative advantage to a cell. ${ }^{37}$ Such a mutant cell may be considered preleukemic, either due to the fact that the first mutation increases its proliferative activity and thus the odds that this preleukemic cell is hit by a second oncogenic event, or alternatively, the first epigenetic mutation may change the epigenetic landscape of a preleukemic cell in such a way that a second mutation is more oncogenic compared with if it had first occurred in an epigenetically unperturbed cell.

This latter scenario should be testable, and would predict that a similar oncogenic insult in an old stem cell would have different pathological consequences compared with if it had first occurred 
in a young cell. There is actually evidence for this; enforced overexpression of Bcr-abl in old stem cells causes different disease kinetics compared with overexpression in young stem cells. ${ }^{38}$ Thus, it is conceivable that leukemia that originates in the elderly is molecularly and functionally distinct from leukemia in young adults.

We expect that many of the questions raised above will be answered in the not too distant future, as more and more laboratories have become interested in the fundamental question as to how a self-renewing stem cell ages.

\section{CONFLICT OF INTEREST}

The authors declare no conflict of interest.

\section{ACKNOWLEDGEMENTS}

Research in the laboratory of Gerald de Haan is supported by grants from the Dutch Organization of Scientific Research (NWO), the Dutch Cancer Society (RUG-2014 7178) and the EU (Marie Curie Initial Training Network MarlAge, Contract number 316964). JJ is supported by a fellowship from the Deutsche Krebshilfe.

JJ Jung, SC Buisman and G de Haan European Research Institute for the Biology of Ageing, University Medical Center Groningen, University of Groningen, Groningen, The Netherlands E-mail: g.de.haan@umcg.nl

\section{REFERENCES}

1 Heron MAR. Changes in the leading cause of death: recent patterns in heart disease and cancer mortality. NCHS Data Brief 2016; 254.

2 Frasca D, Landin AM, Lechner SC, Ryan JG, Schwartz R, Riley RL et al. Aging downregulates the transcription factor $\mathrm{e} 2 \mathrm{a}$, activation-induced cytidine deaminase, and Ig class switch in human B cells. J Immunol 2008; 180: 5283-5290.

3 Goodwin K, Viboud C, Simonsen L. Antibody response to influenza vaccination in the elderly: a quantitative review. Vaccine 2006; 24: 1159-1169.

4 Tettamanti M, Lucca U, Gandini F, Recchia A, Mosconi P, Apolone G et al. Prevalence, incidence and types of mild anemia in the elderly: the 'Health and Anemia' population-based study. Haematologica 2010; 95: 1849-1856.

5 Mosher Kl, Wyss-Coray T. Microglial dysfunction in brain aging and Alzheimer's disease. Biochem Pharmacol 2014; 88: 594-604.

6 Harrison DE. Mouse erythropoietic stem cell lines function normally 100 months: loss related to number of transplantations. Mech Ageing Dev 1979; 9: 427-433.

7 Dykstra B, Olthof S, Schreuder J, Ritsema M, de Haan G. Clonal analysis reveals multiple functional defects of aged murine hematopoietic stem cells. J Exp Med 2011; 208: 2691-2703.

8 Beerman I, Bhattacharya D, Zandi S, Sigvardsson M, Weissman IL, Bryder D et al. Functionally distinct hematopoietic stem cells modulate hematopoietic lineage potential during aging by a mechanism of clonal expansion. Proc Natl Acad Sci 2010; 107: 5465-5470.

9 Walter D, Lier A, Geiselhart A, Thalheimer FB, Huntscha S, Sobotta MC et al. Exit from dormancy provokes DNA-damage-induced attrition in haematopoietic stem cells. Nature 2015; 520: 549-552.

10 Clevers H. The intestinal crypt, a prototype stem cell compartment. Cell 2013; 154: 274-284.

11 Brack AS, Conboy MJ, Roy S, Lee M, Kuo CJ, Keller C et al. Increased Wnt signaling during aging alters muscle stem cell fate and increases fibrosis. Science 2007; 317: 807.

12 Rossi DJ, Bryder D, Zahn JM, Ahlenius H, Sonu R, Wagers AJ et al. Cell intrinsic alterations underlie hematopoietic stem cell aging. Proc Natl Acad Sci USA 2005; 102: 9194-9199.

13 Rozman C, Feliu E, Berga L, Reverter JC, Climent C, Ferran MJ. Age-related variations of fat tissue fraction in normal human bone marrow depend both on size and number of adipocytes: a stereological study. Exp Hematol 1989; 17: 34-37.

14 Birbrair A, Frenette PS. Niche heterogeneity in the bone marrow. Ann NY Acad Sci 2016; 1370: 82-96.
15 Busque L, Mio R, Mattioli J, Brais E, Blais N, Lalonde Y et al. Nonrandom X-inactivation patterns in normal females: lyonization ratios vary with age. Blood 1996; 88: $59-65$.

16 Genovese G, Kähler AK, Handsaker RE, Lindberg J, Rose SA, Bakhoum SF et al. Clonal Hematopoiesis and blood-cancer risk inferred from blood DNA sequence. N Engl J Med 2014; 371: 2477-2487.

17 Xie M, Lu C, Wang J, McLellan MD, Johnson KJ, Wendl MC et al. Age-related mutations associated with clonal hematopoietic expansion and malignancies. Nat Med 2014; 20: 1472-1478.

18 Jaiswal S, Fontanillas P, Flannick J, Manning A, Grauman PV, Mar BG et al. Agerelated clonal hematopoiesis associated with adverse outcomes. $N$ Engl J Med 2014; 371: 2488-2498.

19 Busque L, Patel JP, Figueroa ME, Vasanthakumar A, Provost S, Hamilou Z et al. Recurrent somatic TET2 mutations in normal elderly individuals with clonal hematopoiesis. Nat Genet 2012; 44: 1179-1181.

20 van den Akker EB, Pitts SJ, Deelen J, Moed MH, Potluri S, van Rooij J et al. Uncompromised 10-year survival of oldest old carrying somatic mutations in DNMT3A and TET2. Blood 2016; 127: 1512-1515.

21 Wahlestedt M, Norddahl GL, Sten G, Ugale A, Frisk M-AM, Mattsson R et al. An epigenetic component of hematopoietic stem cell aging amenable to reprogramming into a young state. Blood 2013; 121: 4257-4264.

22 Beerman I, Seita J, Inlay MA, Weissman IL, Rossi DJ. Quiescent hematopoietic stem cells accumulate DNA damage during aging that is repaired upon entry into cell cycle. Cell Stem Cell 2014; 15: 37-50.

23 Zhang S, Yajima H, Huynh H, Zheng J, Callen E, Chen H-T et al. Congenital bone marrow failure in DNA-PKcs mutant mice associated with deficiencies in DNA repair. J Cell Biol 2011; 193: 295-305.

24 Salob SP, Webb DKH, Atherton DJ. A child with xeroderma pigmentosum and bone marrow failure. Br J Dermatol 1992; 126: 372-374.

25 Kamminga LM, Bystrykh LV, de Boer A, Houwer S, Douma J, Weersing E et al. The Polycomb group gene Ezh2 prevents hematopoietic stem cell exhaustion. Blood 2006; 107: 2170-2179.

26 Rizo A, Olthof S, Han L, Vellenga E, de Haan G, Schuringa JJ. Repression of BMI1 in normal and leukemic human CD34+ cells impairs self-renewal and induces apoptosis. Blood 2009; 114: 1498-1505.

27 Rizo A, Dontje B, Vellenga E, de Haan G, Schuringa JJ. Long-term maintenance of human hematopoietic stem/progenitor cells by expression of BMI1. Blood 2008; 111: 2621-2630.

28 Klauke K, Radulovic V, Broekhuis M, Weersing E, Zwart E, Olthof S et al. Polycomb $\mathrm{Cbx}$ family members mediate the balance between haematopoietic stem cell selfrenewal and differentiation. Nat Cell Biol 2013; 15: 353-362.

29 Challen GA, Sun D, Jeong M, Luo M, Jelinek J, Berg JS et al. Dnmt3a is essential for hematopoietic stem cell differentiation. Nat Genet 2012; 44: 23-31.

30 Bowie MB, Kent DG, Dykstra B, McKnight KD, McCaffrey L, Hoodless PA et al. Identification of a new intrinsically timed developmental checkpoint that reprograms key hematopoietic stem cell properties. Proc Natl Acad Sci 2007; 104: 5878-5882.

31 Rebel V, Miller C, Eaves C, Lansdorp P. The repopulation potential of fetal liver hematopoietic stem cells in mice exceeds that of their liver adult bone marrow counterparts. Blood 1996; 87: 3500-3507.

32 Copley MR, Babovic S, Benz C, Knapp DJHF, Beer PA, Kent DG et al. The Lin28blet-7-Hmga2 axis determines the higher self-renewal potential of fetal haematopoietic stem cells. Nat Cell Biol 2013; 15: 916-925.

33 Kim I, Saunders TL, Morrison SJ. Sox17 dependence distinguishes the transcriptional regulation of fetal from adult hematopoietic stem cells. Cell 2007; 130: 470-483.

34 Morin RD, Johnson NA, Severson TM, Mungall AJ, An J, Goya R et al. Somatic mutation of EZH2 (Y641) in follicular and diffuse large B-cell lymphomas of germinal center origin. Nat Genet 2010; 42: 181-185.

35 Kandoth C, McLellan MD, Vandin F, Ye K, Niu B, Lu C et al. Mutational landscape and significance across 12 major cancer types. Nature 2013; 502: 333-339.

36 Langemeijer SMC, Jansen JH, Hooijer J, van Hoogen P, Stevens-Linders E, Massop M et al. TET2 mutations in childhood leukemia. Leukemia 2011; 25: 189-192.

37 Jung J, Buisman S, de Haan G. Hematopoiesis during development, aging, and disease. Exp Hematol 2016; 44: 689-695.

38 Signer RAJ, Montecino-Rodriguez E, Witte ON, McLaughlin J, Dorshkind K. Agerelated defects in $B$ lymphopoiesis underlie the myeloid dominance of adult leukemia. Blood 2007; 110: 1831-1839. 